\title{
NACO/CONSER/SACO \\ Listen-and-Learn \\ Session
}

Presented by

Richard A. Lammert,

Concordia Theological Seminary

Atla PCC Funnels Coordinator

\begin{abstract}
This listen-and-learn session was primarily intended for participants in the Atla funnels for the NACO, CONSER, and SACO programs of the Program for Cooperative Cataloging. It provided an update from the PCC meeting in May, with an opportunity for participants to ask questions about the programs.

The information for this session is based (primarily) on the meeting of the Program for Cooperative Cataloging (PCC) Operations Committee (OpCo) in Washington, DC, May 2-3, 2019. The agenda for that meeting, as well as links to most of the documentation, can be found at this URL: http://www.loc.gov/aba/pcc/documents/OpCo-2019/ Agenda-OpCo-2019.pdf.
\end{abstract}

\section{NACO CJK FUNNEL REFERENCES PROJECT}

In 2008, OCLC prepopulated the LC/NACO Authority File with nonLatin references derived from non-Latin bibliographic headings in OCLC WorldCat. OCLC updated 480,000 NACO records. These records were identified with a 667 field, "Machine-derived nonLatin script reference project." Although it was known that some of the added cross references were incorrect, cleanup work was left as a future project. The NACO CJK Funnel has now picked up this project, identifying 80,956 CJK records that contain multiple nonLatin references. During the course of the project, estimated to last from one to two years, incorrect references will be removed, and the record recoded to RDA (if it is not already RDA-compliant). 


\section{NACO AND INTERNATIONAL LIBRARIES}

The NACO Program is expanding with the addition of international libraries. Library and Archives Canada (LAC) joined the NACO Program in 2017, and the librarians were trained in 2018. Nine universities in the Netherlands (the Netherlands UKB Consortium) joined the NACO Program in 2018. These institutions were trained in 2019. Seven universities in Hong Kong plus the University of Macau joined the NACO Program in 2019. Training was scheduled for May 2019. The inclusion of these libraries in the NACO Program means that there will be more authoritative records for names from these areas of the globe.

\section{OCLC RECORD MANAGER AND NACO}

NACO catalogers should remember that OCLC Record Manager is available for NACO work, and can be used in addition to or instead of Connexion Client. Paul Frank, Coordinator, NACO and SACO Programs, remarked that he found checking records in Record Manager easier than checking them in Connexion Client. Recalling past searches was easier, and the consistent use of the dollar sign for the delimiter simplified input. However (something that Paul did not mention), OCLC does not keep statistics for authority record transactions in Record Manager, so any Atla NACO cataloger using Record Manager will need to be careful to record statistics by hand.

\section{NACO 024 FIELD MORATORIUM}

Attendees at the NACO OpCo were reminded that there is a temporary moratorium on the use of MARC field 024 in authority records. This moratorium is not in official NACO documentation. The reason for the moratorium is that use of the field is dependent on the (eventual) definition and use of subfields $\$ 0$ and $\$ 1$. The Policies Committee of PCC has convened three groups to work on the use of this field: PCC Identity Management TG, Standing Committee on Standards, and Linked Data Advisory Committee. These groups will answer such questions as what sources can be used in the 024 field. 


\section{NACO 672 FIELD}

MARC field 672, "Title Related to the Entity," was added to the MARC authority format in 2013. However, its use has been on hold pending some guidelines for its use. (Atla's "Best Practices" document advises, "Use sparingly until PCC issues guidelines.") Some groups within the PCC are now thinking about the use of this field. However, the recommendations so far do not go further than the best practices established several years ago by Atla: "Use to record a title of a work not expected to be written by the person being established. For example, a book on fly fishing written by a Reformation Historian.” One difficulty that will have to be worked out is that the field is defined to accommodate any type of relationship between a title and an entity, not just the "creator" relationship that we might first think about.

\section{NACO ADVISORY GROUP}

Paul Frank reported that he is creating a NACO Advisory Group that will be composed of five NACO catalogers. These catalogers will be selected by the chair(s) of the PCC Standing Committee on Standards and the PCC Secretariat. The group will operate as a corporate body, responding to NACO-related PCC listserv discussions when a topic is not resolved through member contributions, or when there is a lack of consensus on a particular NACO-related topic. In the past, questions that could not be answered authoritatively by contributors to the list would simply remain unanswered. This group will serve to provide an answer to such questions.

\section{SACO TOPICS}

SACO catalogers should be aware that a new interface is coming to Classification Web. The functionality will be the same, but the look will be somewhat different, providing better ways to navigate the interface. The LCSH Multiples Project is underway, as the Library of Congress removes all bracketed multiples in the Library of Congress Subject Headings (LCSH). Distribution of revised headings began in May. Once a multiples heading has been canceled, new headings will need to be proposed through the SACO subject heading proposal system-which is where Atla SACO catalogers can step in. 


\section{RDA 3R PROJECT}

The OpCo attendees received an update on the RDA 3R Project. The RDA beta site is no longer under constant revision: the project has reached the stabilization phase. This means the site is stable, but not unchanging; changes for mistakes can and will still be made. Stabilization does not mean "official." Several steps have to be taken before the new RDA becomes official. Major translations of the code need to be completed, as well as policy statements completed. After that, the RSC and RDA Board must unanimously agree that the 3R Project is complete. At that point, the one-year countdown clock begins.

\section{DIACHRONIC WORKS IN RDA}

A diachronic work is a work that is planned to be embodied over time, rather than as a single "act of publication." The essence of a diachronic work is a plan for the change of content, which can be done either by accumulation or by replacement. So far (other than the terminology) the concept is well known to catalogers. The new RDA, however, takes a concept from IFLA LRM and applies it to all diachronic works. IFLA LRM (5.8 Modelling of serials) regards any serial as "a distinct instance of the work entity." The new RDA extrapolates the modeling of all diachronic works from this model: any work with a diachronic extension plan may be realized in one and only one expression and embodied in one and only one manifestation. In the new code, Religion past \& present is not a translation of Religion in Geschichte und Gegenwart. It is a new work (albeit related work), a transformation by audience of the original. How this will be represented in MARC remains to be seen.

\section{AGGREGATES IN RDA}

A second area in which catalogers can expect changes is in the area of aggregates. An aggregate is "a manifestation that embodies multiple expressions of works.” Again, the concept is not new, although the terminology is. An example might be the collected poems of Robert Frost. Under the current cataloging code (and all codes up to now, as far as I know), we considered that the volume of poems contained the individual poems. The new RDA redefines the rela- 
tionship between these parts. The aggregating work (the book of all the poems) does not include the content. There is no whole/part relationship between the aggregated works (the individual poems) and the aggregating work (the volume of poems). How this will be represented in MARC remains to be seen. 